\title{
Neuritogenic activity of hot water extract from Hericium erinaceus
}

\author{
Hua $\mathrm{Li}^{1}$, Hye-Jung See ${ }^{1}$, BoKyung Moon ${ }^{2}$, Young-Bok Yoo ${ }^{3}$ and Chan Lee ${ }^{1 *}$ \\ ${ }^{I}$ Department of Food Science and Technology, Chung-Ang University, Anseong, Gyeonggi, 456-756, South Korea \\ ${ }^{2}$ Department of Food and Nutrition, Chung-Ang University, Anseong, Gyeonggi, 456-756, South Korea \\ ${ }^{3}$ Mushroom Research Division, National Institute of Horticultural \& Herbal Science, Rural Development Administration, Bisanro 92 , \\ Eumseong, Chungbuk, 369-873, South Korea
}

(Received August 8, 2013 / Revised September 12, 2013 / Accepted September 16, 2013)

\begin{abstract}
Hot water soluble extract was prepared from Hericium erinaceus and its neuritogenic activity on PC12h cells was analyzed, which is a clone originating from a rat pheochromocytomon. The moisture content of freeze dried hot water extract was $\mathbf{1 2 . 0 8 \%}$. The extract was mainly composed of carbohydrate $(51.24 \%)$ followed by crude protein $(\mathbf{2 4 . 0 4 \%})$, crude fat $(\mathbf{0 . 2 6 \%})$, dietary fiber $(\mathbf{5 . 0 9})$, and ash $(\mathbf{1 2 . 1 8 \%})$. Fatty acids, glucan and inorganic constituents were found as minor components. The neuritogenic activity of hot water extract was evaluated under microscopic observation of neurite outgrowth in $\mathrm{PC12h}$ cells and by measuring the neurite length of induvidual cell. The extract exhibited strong effect of neurite outgrowth in a dose-dependent manner from $0.01 \mathrm{mg} / \mathrm{mL}$ to $1 \mathrm{mg} / \mathrm{mL}$, in which longer neurite outgrowth was observed as the treatment dose increased.
\end{abstract}

KEYWORDS - Hericium erinaceus, Hot water extract, Neuritogenic activity, Proximate composition, PC12h cell

\section{Introduction}

Hericium erinaceus growing on old or dead broadleaf trees is a well-known edible and medicinal mushroom belongs to the Aphyllophorales, Hydnaecae family in oriental countries. The mushroom was called "Yamabushitake" in Japan or "Houtou" in China and it is taken as a food in Japan and China without harmful effects. H. erinaceus was successfully cultivated indoors on conifer sawdust in artificial cultivation (Mizuno et al., 1999a).

Various biological functions of $H$. erinaceus have been investigated in recent years which, related to antimicrobial effect (Kim et al., 2000), anti-tumor activities (Mizuno, 1996b; Mizuno, 2002), immunomodulatory effect (Liu et al., 2002), antioxidant properties (Mau et al., 2002), cytotoxic effects (Kuwahara et al., 1992), hypolipidemic effects and promotion of synthesis of nerve growth factor (NGF) (Kawagishi et al., 1994; Lee et al., 2000). The antimicrobial effect of H. erinaceus extracts and standard antibiotics was quantitatively assessed by the presence of clear zones indicating strong inhibition, and hazy (partial) inhibition zones. However, bacteria were found to be more sensitive to the bioactive compounds compared to $H$. erinaceus (Wong et al., 2009).

A number of bioactive molecules, including antitumor substances, have been identified in $H$. erinaceus. Galactoxyloglucan, xylan and glucoxylan were antitumor and immunostimulating polysaccharides from H. erinaceus (Wasser, 2002). Polysaccharides exert their antitumor effects primarily by activating various immune system responses in the host, such as complement system activation, macrophage-dependent immune system responses, and upregulation of interferon expression. These polysaccharides have various chemical compositions and belong primarily to the $\beta$-glucan group (Lee et al., 2009). H. erinaceus is reported not only to have a hypoglycemic effect but also to reduce the elevation rates of serum triglyceride and total cholesterol levels when administered. The treatment of diabetes often involves medication to control blood glucose levels; some of these medications have undesirable side-effects. Thus, $H$. erinaceus with hypoglycemic effects can be safely

*Corresponding author: chanlee@cau.ac.kr 
used in the management of diabetes (Wang et al., 2005).

Among previously reported biological function of this mushroom, recent research focused on its neuritogenic activity due to the existence of hericenone group which stimulate the synthesis of NGF (Nerve growth factor). Hericenones $\mathrm{C}, \mathrm{D}, \mathrm{E}, \mathrm{F}, \mathrm{G}$ and $\mathrm{H}$ and erinacines $\mathrm{A}, \mathrm{B}, \mathrm{C}, \mathrm{D}, \mathrm{E}, \mathrm{F}, \mathrm{G}, \mathrm{H}$ and $\mathrm{I}$ were isolated from the methanol extract of the fruit body and mycelium of $H$. erinaceus, respectively, all of which promote nerve growth factor(NGF) synthesis in rodent cultured astrocytes. NGF has potent biological activities, such as preventing neuronal death and promoting neurite outgrowth, and is essential to maintain and organize neurons functionally (Obara and Nakahata, 2002). It is assumed that functional deficiency of NGF is related to Alzheimer's disease and plays a role in the etiology of the disease process (Allen and Dawbarn, 2006; Takei et al., 1989). NGFs are proteins which are unable to cross the blood-brain barrier and easily metabolized by peptidases. Therefore, its application as a medicine for treatment of neurodegenerative disorders will be difficult. Alternatively, research has been carried out on low-molecular weight compounds that promote NGF biosynthesis. Recent research has reported neuritogenic activity from edible and medicinal mushroom, such as Tremella fuciformis (Park et al., 2007).

In this study, we investigated proximate composition of $H$. erinaceus and its biological function in hot water extract from $H$. erinaceus. The neuritogenic activity of the extract was investigated using $\mathrm{PC} 12 \mathrm{~h}$ cells and its nerve growth factor (NGF)-like activity was also calculated.

\section{Materials and Methods}

\section{Composition analysis}

1) Analysis of the proximate composition

Proximate analysis of $H$. erinaceus fruiting body and its hot water extract were analyzed to measure content of the crude protein, crude fat, dietary fiber, ash and moisture according to the official AOAC methods.
Moisture was removed by oven dehydration at $105^{\circ} \mathrm{C}$ for $72 \mathrm{~h}$ from sample $(1 \mathrm{~g})$. Ash was determined by weighing the incinerated residue obtained at $550^{\circ} \mathrm{C}$ after $10 \mathrm{~h}$. The dietary fiber content was calculated by combining enzymatic and gravimetric methods. Each of the samples was analyzed using the AOAC TDF method (Prosky et al., 1988) to provide duplicate samples for nitrogen and ash determination. In brief, aliquots of samples $(1 \mathrm{~g}$ of dry matter) were treated with $100 \mu \mathrm{L}$ thermostable $\alpha$-amylase $(3,000 \mathrm{U} / \mathrm{mL}$, Megazyme, Wicklow, Ireland) for $30 \mathrm{~min}$ at $150 \mathrm{rpm}$ in a boiling water bath $\left(95^{\circ} \mathrm{C}\right)$ and an purified protease $(50 \mathrm{mg} / \mathrm{mL}$, Megazyme, Wicklow, Ireland) for $30 \mathrm{~min}$ at $150 \mathrm{rpm}$ at $65^{\circ} \mathrm{C}$ to solubilize protein and amyloglucosidase (3300 U/mL, Megazyme, Wicklow, Ireland) for 30 min at $150 \mathrm{rpm}$ at $65^{\circ} \mathrm{C}$ to remove glycogen. After a 90\% ethanol precipitation, the ethanol-insoluble residue recovered by filtration was dried and weighed, and the weight was corrected for ash and residual protein content. Crude fat content of the samples was estimated by exhaustive Soxhlet extraction of a known weight of dried sample with ethyl ether (b.p. $40 \sim 60^{\circ} \mathrm{C}$ ) for $8 \mathrm{~h}$ (A.O.A.C. 7.045, 1975). Finally, crude protein was determined by a micro-Kjeldahl method, and a conversion factor of 6.25 was used to quantify the nitrogen percentage of the crude protein. The percentage of all the fractions (crude protein, crude fat, moisture and ash) were added together and subtracted from 100 to obtain the total carbohydrate percentage.

\section{2) Analysis of glucans}

The total glucan contents were quantified following enzymatic hydrolysis with exo-1,3- $\beta$-glucanase (200 U/mL, Megazyme, Wicklow, Ireland) and $\beta$ glucosidase ( $4 \mathrm{U} / \mathrm{mL}$, Megazyme) by modified AOAC methodology for mushrooms. The $\beta$-glucan contents were determined according to contents of $\beta$ glucan. The $\beta$-glucans are solubilised in concentrated potassium hydroxide $(2 \mathrm{~N})$ from sample $(100 \mathrm{mg})$. And then the samples were treated with $0.2 \mathrm{~mL}$ of amyloglucosidase $(1630 \mathrm{U} / \mathrm{mL}$, Megazyme, Wicklow, Ireland) plus invertase $(500 \mathrm{U} / \mathrm{mL}$, Megazyme, Wicklow, Ireland). The samples were incubated at $40^{\circ} \mathrm{C}$ 
for $30 \mathrm{~min}$ at $150 \mathrm{rpm}$. Samples were read on a UV-visible spectrophotometer (Uvikon 933, Milan, Italy) at $510 \mathrm{~nm}$. The percentage of $\beta$-glucans were subtracted from total glucan contents to $\beta$-glucan contents.

\section{3) Analysis of fatty acids composition}

Sample $(1 \mathrm{~g})$ added pyrogallol solution $(50 \mathrm{mg} / \mathrm{mL})$ was extracted with diethyl ether/petroleum ether (1:1) on water bath at $80^{\circ} \mathrm{C}$ at $120 \mathrm{rpm}$ for $1 \mathrm{~h}$. The fatty acids in the extract were simultaneously hydrolyzed and derived to their methyl ester forms with $1 \mathrm{~mL}$ of $\mathrm{NaOH} /$ methanol at $85^{\circ} \mathrm{C}$ for $10 \mathrm{~min}$ and then a complete derivation was added with $1 \mathrm{~mL}$ of $\mathrm{BF}_{3}(14 \%)$ at $85^{\circ} \mathrm{C}$ for $10 \mathrm{~min}$. And then the sample evaporated to dryness under a stream of nitrogen. Individual samples were passed through an anhydrous $\mathrm{Na}_{2} \mathrm{SO}_{4}$ column and redissolved in $3 \mathrm{~mL}$ of iso-octane. The derived free fatty acids were separated in An Agilent Technologies $7890 \mathrm{~N}$ gas chromatograph equipped with a flame ionization detector and a fused silica capillary column $\left(\mathrm{SP}^{\mathrm{TM}}-2560,100 \mathrm{~m} \times 0.25 \mathrm{~mm}\right.$ i.d. $\times 0.2 \mu \mathrm{m}$ film thickness, Supelco, Bellefonte, PA) with a stationary phase of 5\% phenyl methyl silicon. Operating conditions were as follows: Helium was the carrier gas $(1 \mathrm{~mL} / \mathrm{min})$, detector $\left(285^{\circ} \mathrm{C}\right)$, injector $\left(225^{\circ} \mathrm{C}\right)$, and injected volume $(1 \mu \mathrm{L})$.

\section{4) Analysis of inorganic constituents}

Inorganic constituents were determined by first destroying the organic matter in the dried sample. Calcium, sodium, potassium, iron and phosphorus was determined speetrophotometrically (A.O.A.C. 3.064, 1975). Sample $(0.5 \mathrm{~g})$ added $\mathrm{H}_{2} \mathrm{O}_{2}(3 \mathrm{~mL})$ and $\mathrm{AgNO}_{3}$ $(5 \mathrm{~mL})$ was roasted in an Microwave at $200^{\circ} \mathrm{C}$ to determine $\mathrm{K}, \mathrm{Ca}, \mathrm{Na}, \mathrm{Fe}$, and $\mathrm{P}$. After roasting, samples were placed in a beaker and were diluted distilled water (final weight: $15 \mathrm{~g}$ ). The $\mathrm{Na}$ and $\mathrm{Ca}$ contents were determined by ame photometer, and $\mathrm{Cu}, \mathrm{Zn}, \mathrm{Mn}$, and $\mathrm{Fe}$ by Inductively Coupled Plasma Spectrometer (OPTIMA 5300 DV, PerkinElmer, U.S.A)

\section{Neuritogenic activity of $H$. erinaceus hot water extract}

1) Preparation of hot water extract from H. erinaceus
The hot water extract of $H$. erinaceus fruiting body was obtained as follows: freeze-dried mushroom $(50 \mathrm{~g})$ was milled into powder using a food mixer, and the mushroom powder was extracted with water 6 hours at $100^{\circ} \mathrm{C}$. The extract was centrifuged at $10000 \mathrm{rpm}$ (using Vision scientific Co. Ltd., VS-24SMTi) for $40 \mathrm{~min}$ at $4^{\circ} \mathrm{C}$. Supernatant was collected and filtered twice through No.4 Whatman filter paper, and filterate was evaporated at $40^{\circ} \mathrm{C}$. And then the extract was freeze-dried for $48 \mathrm{~h}$.

2) Cell culture

PC12h cells, a subclone of PC12 cells isolated by Dr. Hatanaka (Hatanaka, 1981) and kindly donated by Pulmuone Co., Ltd. (Institute of Food \& Culture R\&D Center, Pulmuone Co., Ltd., Seoul, Korea), were grown in Dulbecco's modified Eagle's medium (DMEM, Gibco) supplemented with 5\% (v/ v) horse serum and $5 \%(\mathrm{v} / \mathrm{v})$ fetal bovine serum in a $100 \mathrm{~mm}$ petri dish coated with collagen (Type I, Sigma, U.S.A.) under $10 \% \mathrm{CO}_{2}$ at $37^{\circ} \mathrm{C}$. PC12h cells undergo certain NGF-responsive cellular events, including neurite outgrowth. PC12h cells are much more sensitive to NGF than PC12 cells (Hatanaka, 1983).

3) Assay for neuritogenic activity in PC12h cells.

Sample preparation: H. erinaceus hot water extract was prepared through $0.22 \mu \mathrm{m}$ syringe driven filter (Millex HV, Millipore, France). The concentration of $H$. erinaceus hot water extract were $0.01 \mathrm{mg} / \mathrm{mL}$, $0.1 \mathrm{mg} / \mathrm{mL}, 0.5 \mathrm{mg} / \mathrm{mL}$, and $1 \mathrm{mg} / \mathrm{mL}$. Also, the yogurts were centrifugated at $10,000 \mathrm{rpm}$ for $30 \mathrm{~min}$ at $4^{\circ} \mathrm{C}$ into sterile sealed tubes. Supernatant was collected and filtered twice through No.4 Whatman filter paper, and then filterate was freeze-dried for 48hours.

For morphological studies, cells were plated in 6 well plates coated with collagen at a density of $2 \times 10^{5}$ cells in $2 \mathrm{~mL}$ medium per dish. After $48 \mathrm{~h}$ of culture, the medium was replaced with serum-free DMEM/Ham'sF12 (1:1) medium (DMEM/F12,Gibco) supplemented with sodium selenite $(30 \mu \mathrm{m} / \mathrm{L})$, transferrin $(10 \mathrm{mg} / \mathrm{mL})$, insulin $(10 \mathrm{mg} / \mathrm{mL})$, progester- 
one $(256.1 \mu \mathrm{g} / \mathrm{mL})$, and hot water extract $H$. erinaceus. On the other hand, Nerve growth factor (sigma-Aldrich, St. Louis, USA) $0.1 \mu \mathrm{g} / \mathrm{mL}$ was used negative control. And positive control was distilled water filtered through $0.22 \mu \mathrm{m}$ syringe driven filter (Millex HV, Millipore, France). After 48 h, the neuritogenic activity was evaluated by measuring the length of the longest neurite of individual cells using an image processor system (Leica Qwin, Germany) attached to a phase-contrast microscope. One hundred cells in at least 10 random fields in two culture dishes were measured, with the values averaged.

\section{Results and Discussions}

\section{Composition analysis of $\boldsymbol{H}$. erinaceus and its}

\section{hot water extract}

The proximate composition of $H$. erinaceus and its hot water extract are shown in Table 1. The freeze dried $H$. erinaceus showed moisture content of $4.80 \%$. The mushroom was mainly composed of dietary fiber $(31.35 \%)$ followed by crude protein $(25.71 \%)$, carbohydrate $(25.65 \%)$, ash $(9.01 \%)$ and crude fat $(3.44 \%)$. On the other hand, the $H$. erinaceus hot water extract showed moisture content of $12.09 \%$. Main components of $H$. erinaceus hot water extact were followed by carbohydrate $(51.24 \%)$, crude protein $(24.21 \%)$, ash $(12.18 \%)$, dietary fiber $(5.09 \%)$ and crude fat $(0.26 \%)$. Considerable differences between freeze dried $H$. erinaceus and its hot water extract weren't apparent. Ko et al. (1999) reported the protein content of freeze-dried shiitake mushroom is $18.12 \%$. The protein content of $H$. erinaceus was high compared to shiitake mushroom and other mushrooms (Kalac, 2009).

The glucan contents of $H$. erinaceus and its hot water extract are shown in Table 2. Glucan contents of this mushroom were $7.62 \%, \beta$-glucan contents were $7.20 \%$. Also glucan contents of hot water extract were $2.65 \%$ and $\beta$-glucan contents were $2.19 \%$ Great attention has recently been paid to mushroom $\beta$-glucans, due to their health-positive effects. $\beta$-glucan research and applications have
Table 1. Proximate composition $(\mathrm{g} / 100 \mathrm{~g})^{1}$ of freeze-dried $H$. erinaceus and its hot water extract

\begin{tabular}{ccc}
\hline \hline $\begin{array}{c}\text { Proximate } \\
\text { composition }\end{array}$ & $\begin{array}{c}\text { Freeze-dried } \\
\text { H. erinaceus }\end{array}$ & $\begin{array}{c}\text { H .erinaceus } \\
\text { hot water extract }\end{array}$ \\
\hline Carbohydrate & $25.65 \pm 2.075$ & $51.24 \pm 1.22$ \\
Crude protein & $25.71 \pm 0.23$ & $24.21 \pm 0.23$ \\
Crude fat & $3.44 \pm 0.89$ & $0.26 \pm 0.00$ \\
Dietary fiber & $31.35 \pm 1.79$ & $5.09 \pm 0.87$ \\
Ash & $9.01 \pm 0.66$ & $12.18 \pm 0.79$ \\
Moisture & $4.80 \pm 0.28$ & $12.09 \pm 0.19$ \\
\hline
\end{tabular}

${ }^{1}$ Average \pm standard deviation, $\mathrm{n}=3$

Table 2. Glucans composition $(\mathrm{g} / 100 \mathrm{~g})^{1}$ of freeze-dried fruiting body of $H$. erinaceus and its hot water extract

\begin{tabular}{ccc}
\hline \hline Glucans & $\begin{array}{c}\text { Freeze-dried } \\
\text { H. erinaceus }\end{array}$ & $\begin{array}{c}\text { H. erinaceus } \\
\text { hot water extract }\end{array}$ \\
\hline$\alpha$-glucan & $0.421 \pm 0.010$ & $0.459 \pm 0.075$ \\
$\beta$-glucan & $7.204 \pm 0.702$ & $2.194 \pm 0.260$ \\
Total glucan & $7.625 \pm 0.693$ & $2.653 \pm 0.189$ \\
\hline
\end{tabular}

${ }^{1}$ Average \pm standard deviation, $\mathrm{n}=3$

Table 3. Fatty acids composition $(\mathrm{g} / 100 \mathrm{~g})^{1}$ of freeze-dried fruiting body of $H$. erinaceus and its hot water extract

\begin{tabular}{ccc}
\hline \hline Fatty acids & $\begin{array}{c}\text { Freeze-dried } \\
\text { H. erinaceus }\end{array}$ & $\begin{array}{c}\text { H. erinaceus } \\
\text { hot water extract }\end{array}$ \\
\hline $\begin{array}{c}\text { Saturates } \\
\text { Mono-unsaturates } \\
\text { Linolein Acid } \\
(\mathrm{C} 18: 2 \mathrm{n}-6)\end{array}$ & $0.186 \pm 0.014$ & $0.095 \pm 0.0002$ \\
Total fatty acids & $0.806 \pm 0.014$ & $0.133 \pm 0.0003$ \\
\hline
\end{tabular}

${ }^{1}$ Average \pm standard deviation, $\mathrm{n}=3$

been successful, mainly in the east-Asian countries and deal mostly with cultivated mushroom species (Wasser, 2002).

The fatty acids of $H$. erinaceus and its hot water extract are shown in Table 3. Fatty acids contents $(0.806 \%)$ of this mushroom were low. Very high proportions were found Linolein acid (C18:2n-6) in freeze-dried $H$. erinaceus and its hot water extract. The nutritional value of this mushroom lipid is limited, due to low total lipid contents and the absence of desirable n-3 fatty acids.

Major inorganic constituents of $\mathrm{H}$. erinaceus and its hot water extract are given in Table 4. The inorganic constituents in freeze dried $H$. erinaceus were on the whole slightly lower than its hot water 
Table 4. Inorganic constituents composition $(\mathrm{mg} / 100 \mathrm{~g})^{1}$ of freezedried fruiting body of Hericium erinaceus and its hot water extract

\begin{tabular}{ccc}
\hline \hline $\begin{array}{c}\text { Inorganic } \\
\text { constituents }\end{array}$ & $\begin{array}{c}\text { Freeze-dried } \\
\text { H. erinaceus }\end{array}$ & $\begin{array}{c}\text { H. erinaceus } \\
\text { hot water extract }\end{array}$ \\
\hline $\mathrm{Na}$ & $1.273 \pm 0.041$ & \\
$\mathrm{~K}$ & $1515.000 \pm 24.042$ & $1992.500 \pm 487.196$ \\
$\mathrm{Fe}$ & $0.669 \pm 0.007$ & $0.232 \pm 0.004$ \\
$\mathrm{Ca}$ & $2.402 \pm 0.566$ & $10.936 \pm 0.601$ \\
$\mathrm{P}$ & $463.200 \pm 9.617$ & $572.075 \pm 18.773$ \\
\hline
\end{tabular}

${ }^{1}$ Average \pm standard deviation, $\mathrm{n}=3$

Table 5. Usual content (mg/100g) of major inorganic constituents in mushrooms

\begin{tabular}{cc}
\hline \hline Inorganic constituents & Usual content \\
\hline $\mathrm{Na}$ & $10-40$ \\
$\mathrm{~K}$ & $2000-4000$ \\
$\mathrm{Ca}$ & $10-50$ \\
$\mathrm{P}$ & $500-1000$ \\
\hline
\end{tabular}

(Pavel Kalac, 2009)

extract, except Iron. Kalac (2009) reported content of major inorganic constituents in mushrooms (Table 5). According to Kalac (2009), H. erinaceus and its hot water extract contain non-specific levels of inorganic constituents. But, inorganic constituents of this mushroom are somewhat higher or comparable with the most vegetables.

\section{Neuritogenic activity of $\boldsymbol{H}$. erinaceus hot water extract}

Hot water soluble extract was prepared from $H$. erinaceus and its neuritogenic activity on $\mathrm{PC} 12 \mathrm{~h}$ cells was analyzed, which is a clone originating from a rat pheochromocytomon. NGF has been reported to induce morphological changes in PC12h cells by improving neurite outgrowth (Hatanaka, 1983). NGF was shown to improve the differentiation of $\mathrm{PC} 12 \mathrm{~h}$ cells (Fig. 1; Table 6). The average neurite length of cells treated with $0.1 \mu \mathrm{g} / \mathrm{mL}$ of NGF is $49.01 \pm 11.06 \mu \mathrm{m}$. After treatment of PC12h cells with the hot water extract of $H$. erinaceus at a concentration range of 0.1 and $1 \mu \mathrm{g} / \mathrm{mL}$ for $48 \mathrm{~h}$, the longest neurite length of each cell was measured (Fig. 1; Table 6). They were significant increase in differentiation com- (a)

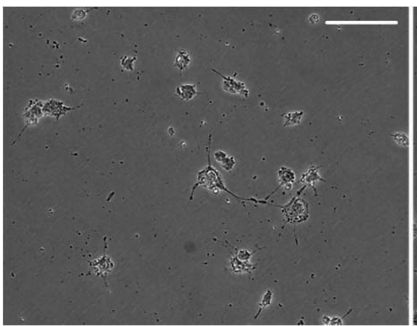

(c)

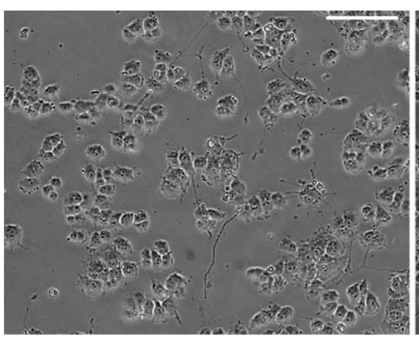

(e)

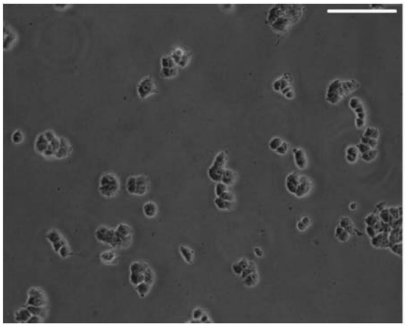

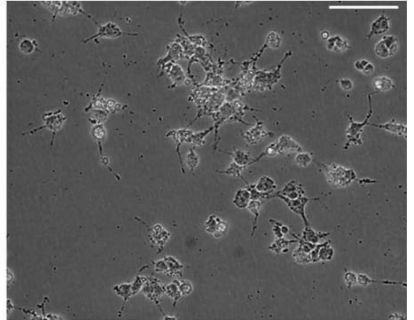

(b)

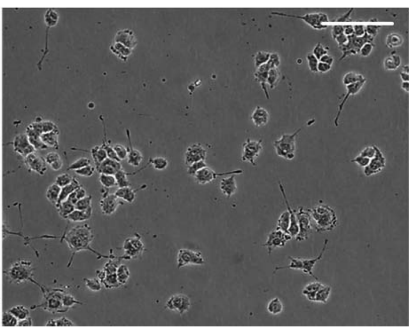

(d)

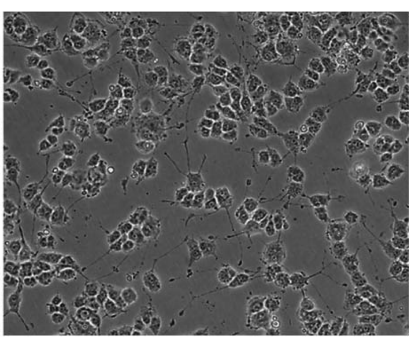

(f)
Fig. 1. Neuritogenesis induced by NGF in $\mathrm{PC} 12 \mathrm{~h}$ cells (*200). Scale bar $=100 \mu \mathrm{m}$ (a) Control (negative vehicle); (b) NGF $0.10 \mu \mathrm{g} / \mathrm{mL}$. Morphological changes induced hot water extract of $\mathrm{H}$. erinaceus in $\mathrm{PC} 12 \mathrm{~h}$ cells. Scale bar $=100 \mu \mathrm{m}$. $(* 200)$; (c) Hot water extract of $H$. erinaceus $0.01 \mathrm{mg} / \mathrm{mL}$; (d) Hot water extract of H. erinaceus $0.10 \mathrm{mg} / \mathrm{mL}$; (e) Hot water extract of $H$. erinaceus $0.50 \mathrm{mg} / \mathrm{mL}$; (f) Hot water extract of $H$. erinaceus $1.00 \mathrm{mg} / \mathrm{mL}$.

Table 6. Effect of $H$. erinaceus hot water extract on $\mathrm{PC} 12 \mathrm{~h}$ cells neuritogenesis

\begin{tabular}{ccc}
\hline \hline & & Neurite length (ìm) \\
\hline \multicolumn{2}{c}{ Control } & $12.931 \pm 2.281$ \\
NGF $0.10 \mu \mathrm{g} / \mathrm{mL}$ & $49.013 \pm 11.058$ \\
& $0.01 \mathrm{mg} / \mathrm{mL}$ & $24.639 \pm 4.728$ \\
Concentration of & $0.10 \mathrm{mg} / \mathrm{mL}$ & $44.569 \pm 6.891$ \\
H. erinaceus hot & $0.50 \mathrm{mg} / \mathrm{mL}$ & $62.989 \pm 7.783$ \\
water extract & $1.00 \mathrm{mg} / \mathrm{mL}$ & $76.353 \pm 13.853$ \\
\hline
\end{tabular}

Average \pm standard deviation, $\mathrm{n}=100$

pared to the neurite length of the control. The average the longest neurite length of cells treated with $1 \mathrm{mg} / \mathrm{mL}$ of $H$. erinaceus is $76.35 \pm 13.85 \mu \mathrm{m}$. The hot water extract of $H$. erinaceus exerts neu- 
ronal differentiation activity in $\mathrm{PC} 12 \mathrm{~h}$ cells by inducing neurite outgrowth at low concentration $(0.1 \mathrm{mg} / \mathrm{mL})$ compared to nerve growth factor $(0.1 \mu \mathrm{g} / \mathrm{mL}$ of NGF).

Park et al. (2007) reported that the hot water extract of Tremella fuciformis tends to induce neurite outgrowth in $\mathrm{PC} 12 \mathrm{~h}$ cells. Also Park et al. (2006) reported the neuritogenic activity of genipin containing fraction from Korean gardenia fruit previously. When PC12h cells were treated with $5 \mu \mathrm{g} / \mathrm{mL}$ of genipin containing fraction from Korean gardenia fruit, they observed similar neuritogenic activity compared to $1 \mu \mathrm{g} / \mathrm{mL}$ of hot water extract of $T$. fuciformis. The average neurite length of cells treated with $1 \mu \mathrm{g} / \mathrm{mL}$ of hot water extract of $T$. fuciformis is $77.84 \pm 0.92 \mu \mathrm{m}$.

\section{Conclusion}

In this study hot water extract of $H$. erinaceus fruiting body was prepared and analyzed. As a result of hot water extract analysis, the proximate composition, glucans, fatty acids and inorganic constituents were similar to freeze-dried $H$. erinaceus. In neuritogenic activity of hot water extract, hot water extract exhibited neurite outgrowth on $\mathrm{PC} 12 \mathrm{~h}$ cells. Treatment of PC12 cells with NGF induced neuronal differentiation. Also, treatment of $\mathrm{PC} 12 \mathrm{~h}$ cells with hot water extract did. These results suggest the possibility using hot water extract $H$. erinaceus derivatives as NGF substitutes. The degree of neurite outgrowth activity differed among the compound concentration. In $1 \mathrm{mg} / \mathrm{mL}$ hot water extract exhibited the highest neuritogenic effect and the lowest neuritogenic effect is $0.01 \mathrm{mg} / \mathrm{mL}$. It means neuritogenic effect depends on the concentration of hot water extract.

\section{Acknowledgement}

This work was supported by the GRRC program of the Gyeonggi province (GRRC-CAU-2013-B01) and the development of mushroom products and related functional resources of the Rural Development Administration (PJ907021102013), Republic of Korea.

\section{Reference}

Allen, S. J. and Dawbarn, D. 2006. Clinical relevance of the neurotrophins and their receptors. Clin. Sci. 110 : 175-191.

Hatanaka, H. 1981. Nerve growth factor-mediated stimulation of tyrosine hydroxylase activity in clonal rat pheochromocytoma cell line. Brain Res. 22 : 225-233.

Hatanaka, H. 1983. Nerve growth factor-mediated differentiation of a nerve cell line cultured in a hormone-supplemented serum free medium. Dev. Brain Res. 6 : 243-250.

Kalac, P. 2009. Chemical composition and nutritional value of European species of wild growing mushrooms: A review. Food Chem. 113 : 9-16.

Kawagishi, H., Shimada, A., Shirai, R., Okamoto, K,. Ojima, F., Sakamoto, H., Ishiguro, Y. and Furukawa, S. 1994. Erinacines A, B and C, strong stimulators of nerve growth factor (NGF)-synthesis, from the mycelia of Hericium erinaceum. Tetrahedron Lett. 35 : 1569-1572.

Kim, D. M., Pyun, C. W., Ko, H. G. and Park, W. M. 2000. Isolation of antimicrobial substances from Hericium erinaceum. Mycobiology. 28 : 33-38.

Kuwahara, S., Morihino, E., Nemoto, A. and Hiramatsu, A. 1992. Synthesis and absolute configuration of a cytotoxic fatty acid from the mushroom Hericium erinaceum. Biosci. Biotechnol. and Biochem. 56 : 1417-1419.

Ko, J. W., Lee, W. Y., Lee, J. H., Ha, Y. S. and Choi, Y. H. 1999. Absorption characteristics of dried Shiitake mushrooms powder using different drying methods. Korean J. Food Sci. Technol. 31(1) : 128-137.

Lee, E. W., Shizuki, K., Hosokawa, S., Suzuki, M., Suganuma, H., Inakuma, T., Li, J., Ohnishi-Kameyama, M., Nagata, T., Furukawa, S. and Kawagishi, H. 2000. Two novel diterpenoids, erinacines $\mathrm{H}$ and $\mathrm{I}$ from the mycelia of Hericium erinaceum. Biosci. Biotechnol. and Biochem. 64 : 2402-2405.

Lee, J. S., Kyoung, M. M., Cho, J. Y. and Hong, E. K. 2009. Study of macrophage activation and structural characteristics of purified polysaccharides from the fruiting body of Hericium erinaceum, J Microbiol. and Biotechnol. 19(9) : 951-959.

Liu, C. P., Fang, J. N. and Xiao, X. Q. 2002. Structural characterization and biological activities of SC4, an acidic polysaccharide from Salvia chinensis. Acta Pharm. Sinic. 23(2) : 162-166.

Mizuno, T. 1999a. Bioactive substances in Hericium erinaceus pers and its medicinal utilization. Int. J Med. Mush. 1 : 105-119.

Mizuno, T. 1999b. The extraction and development of antitumoractive polysaccharides from medicinal mushrooms in Japan. Int. J Med. Mush. 1 : 9-29

Mizuno, T. 2002. Medicinal properties and clinical effects on Agaricus blazei Murr. Int. J Med. Mush. 4

Mau, J. L., Lin, H. C. and Song, S. F. 2002. Antioxidant properties of several specialty mushrooms. Food Res. Int. 35 : 519-526.

Obara. Y. and Nakahata, N. 2002. The signaling pathway of neurotropic factor. Drug News and Perspect. 15 : 290298. 
Park, K. J., Lee, S. Y., Kim, H. S., Yamazaki, M., Kenzo, C. and Ha, H. C. 2007. The Neuroprotective and Neurotrophic Effects of Tremella fuciformis in $\mathrm{PC} 12 \mathrm{~h}$ Cells. Mycobiology. 35(1) : 11-15.

Park, K. J., Ha, H. C., Kim, H. S., Chiba, K., Yeo, I. H. and Lee, S. Y. 2006. The Neuroprotective and Neurotrophic Effects of Korean Gardenia jasminoides Ellis in PC12h cells. Food Sci. Biotechnol. 15 : 735-738.

Prosky, L., Asp, N-G., Schweizer, T. F., DeVires, J. W. and Furda, I. 1988. Determination of insoluble, soluble and total dietary fiber in foods and food products: interlaboratory study. J. Assoc. Off. Anal. Chem. 71 : 1017-1023.

Takei, N., Tsukui, H. and Hatanaka, H. 1989. Intracellular storage and evoked release of acetylcholine from postnatal rat basal forebrain cholinergic neurons in culture with nerve growth factor. J Neurochem. 53 : 1405-1410.

Wang, J., Hu, S. H., Wang, J. T., Chen, K. S. and Chia, Y. C. 2005. Hypoglycemic effect of extract of Hericium erinaceus. J Sci. Food and Agricul. 85 : 641-646.

Wasser, S. P. 2002. Medicinal mushrooms as a source of antitumor and immunomodulating polysaccharides. Applied Microbiol. and Biotechnol. 60 : 258-274.

Wong, K. H., Vikineswary, S., Noorlidah, A., Kuppusamy, U. R. and Murali, N. 2009. Antimicrobial and antioxidant activities of Hericium erinaceus, Food Technol. and Biotechnol. 47(1) : 47-55. 